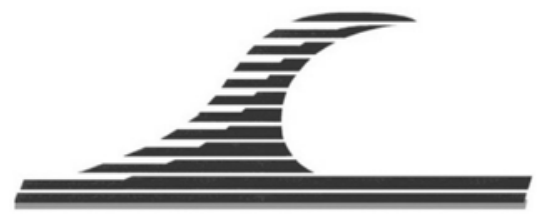

Revue Paralia, Volume 8 (2015) pp s02.1-s02.8

Keywords: Suspended sediment, Vertical profile of the concentration, Non-uniform flow, Transitory state, Deposition, Erosion, Mud, Sand, Model $\alpha-\beta$ (C) Editions Paralia CFL

\title{
Transitory distribution of the suspended sediment in a unidirectional non-uniform flow
}

\section{Martin SANCHEZ ${ }^{1}$}

1. University of Nantes, UMR 6112 CNRS, LPG (Lab. Planetology \& Geodynamics), 2 rue de la Houssinière, BP 92208, 44322 Nantes cedex 3, France.

martin.sanchez@univ-nantes.fr

\begin{abstract}
:
A $1 \mathrm{DH}$ modeling is implemented to study a particular case of transport in suspension along a channel corresponding to a $2 \mathrm{DV}$ problem. In order to include the vertical dimension, a model named $\alpha-\beta$ is used. This latter was developed to describe the vertical distribution of suspended sediment in a flow corresponding to an unsteady and/or non-uniform state, and including deposition and resuspension phenomena (SANCHEZ, 2013). Results show that in some regions of the studied domain, the $\alpha-\beta$ model describing the vertical distribution of suspended sediment, can be simplified because its two parameters ( $\alpha$ and $\beta$ ) remain constant.
\end{abstract}

Translated version of a paper in French (DOI reference: http://dx.doi.org/10.5150/cmcm.2015.016), presented during the edition 3 of the Coastal and Maritime Mediterranean Conference,

(25-27 November 2015) in Ferrara, Italy. Received 02 October 2015, accepted 11 December 2015, available online 30 January 2016. 


\section{Introduction}

Current 2DH hydrodynamic models allow applications on very long periods with fine geometric scale meshes. For these reasons, practical applications on real problems make extensive use of $2 \mathrm{DH}$ models. If the variables of the problem are properly integrated onto the vertical coordinate, the results of these models are close to those from the best 3D models. In several types of problem, the vertical dimension can be considered in a realistic and precise manner by this way. Here are two examples:

a) In the wave propagation models describing the vertical distribution of the velocity potential by Stokes-Airy theory (BERKHOFF, 1972).

b) In hydrodynamic flow models that integrate onto the full depth the effect of shear stress on the mean flow velocities (SAINT-VENANT, 1871).

Thanks to the $\alpha-\beta$ model, which was recently developed (SANCHEZ, 2013), an accurate description of the vertical distribution of sediment in the water column can be obtained. That enables the use of 2DH models for the simulation of sediment transport taking into account (i) aspects linked to a transitory state, (i) convective-diffusive vertical mixing, and (iii) solid exchanges with the bottom (sediment erosion and/or deposition).

The first validations of the $\alpha$ - $\beta$ model were carried out for unsteady states and low settling velocities $W\left(0.05<W\left(\mathrm{~mm} \mathrm{~s}^{-1}\right)<3.2\right)$, which characterizes fine sediments (SANCHEZ, 2013). Subsequently this model was successfully used to simulate the transport in suspension of sand and gravel, under cyclical hydrodynamic actions in a wide range of periods $T(2.5<T(\mathrm{~s})<\infty)$, (SANCHEZ, 2014).

The purpose of this article is to study the suspended sediment transport along a channel for non-uniform states. The studied configuration can represent either a river discharging into a lake or an estuary connected with a microtidal sea.

\section{Theory for an equilibrium state}

If the sedimentary state is uniform and steady, the vertical distribution of the suspended sediment concentration $C$ is governed by:

$W C=-K_{z} \frac{\partial C}{\partial z}$

where $W$ is the local mean value of the suspended sediment settling velocity, $z$ is the vertical coordinate and $K_{z}$ is the turbulent diffusion coefficient in the $\mathrm{Oz}$ direction. In the following equations it is assumed that the bottom is located at $z=0$.

In this study, the physical magnitudes $W$ and $K_{z}$ are considered to be invariants with $z$. This hypothesis is a simplification of the problem widely used in practical applications. So, for a sedimentary equilibrium state, the expression for the concentration is:

$\dddot{C}\left(z^{\circ}\right)=C(0) \exp \left(-\alpha_{\infty} z^{\circ}\right)$ 
where $z^{\circ}=z / d$ is the non dimensional vertical coordinate, $d$ the depth and $\alpha_{\infty}$ the Peclet number characterizing the vertical convection-diffusion sediment transfers:

$\alpha_{\infty}=\frac{W d}{K_{z}}$

One usual relation to evaluate $K_{z}$ retained for this study is:

$K_{z}=\frac{\kappa}{6} U_{c} d$

where $U_{c}$ is the shear velocity and $\kappa \approx 0,4$ the universal Karman constant.

\section{Presentation of the $\alpha-\beta$ model (SANCHEZ, 2013)}

Numerical tests carried out during the initial step of validation of the $\alpha$ - $\beta$ model, show that the concentration $C$ is not well represented by equation 2 for marked transitory hydrodynamic states, even when erosion and deposition are not observed. In agreement with the $\alpha$ - $\beta$ model, for this specific case concerning transitory states, the concentration, which is then denoted $\widetilde{C}$, is correctly modeled by the following equation:

$\widetilde{C}\left(z^{\circ}\right)=C(0) \exp \left(-\alpha z^{\circ}\right)$

where $\alpha$ is a parameter whose value always trends to $\alpha_{\infty}$ in accordance with a phenomenological model, which for a unidirectional 1DH flow (direction $O x$ ), is written as:

$\frac{\partial \alpha}{\partial t}+\bar{V}_{x} \frac{\partial \alpha}{\partial x}=c_{\alpha} \frac{U_{c}}{d}\left(\alpha_{\infty}-\alpha\right)$

where $\bar{V}_{x}$ is the vertical mean velocity of the flow in the $O x$ direction, and $c_{\alpha} \approx 0.667$ is the coefficient of the model.

In most cases, the modifications on the vertical concentration profile induced by deposition and erosion (see Figure 1), are more significant that that produced by the transitory state of the hydrodynamic variables. It is shown that in a general case the profile of $C$ is well described by (SANCHEZ, 2013):

$C\left(z^{\circ}\right)=C_{R} \exp \left(-\alpha z^{\circ}\right) \exp \left(-\beta\left(1-z^{\circ}\right)^{2}\right)$

where $C_{R}$ is a reference concentration and $\beta$ is a parameter of the model whose value always trends to $\beta_{\infty}$ in accordance with the following phenomenological model including a coefficient $c_{\beta}$ :

$\frac{\partial \beta}{\partial t}+\bar{V}_{x} \frac{\partial \beta}{\partial x}=c_{\beta} \frac{U_{c}}{d}\left(\beta_{\infty}-\beta\right)$

where $\beta_{\infty}$ is the instantaneous terminal value of the parameter $\beta$, which depends on the solid exchanges between the bed and the water column. These exchanges are parameterized by either the deposition rate $D^{e f}$ (sediment sink term in $\mathrm{kg} \mathrm{m}^{-2} \mathrm{~s}^{-1}$ ) or the erosion rate $E^{\text {ef }}$ (sediment source term in $\mathrm{kg} \mathrm{m}^{-2} \mathrm{~s}^{-1}$ ).

In what follows, the solid exchanges at the bottom are parameterized by a unique exchange rate $S^{e f}$, which is equal to $D^{e f}$ in case of deposition and to $-E^{e f}$ in case of 
erosion. Moreover, a law by KRONE (1986) is generalized in order to define a nondimensional rate for the solid exchanges with the bed:

$$
p=\frac{S^{e f}}{W \times C(0)}
$$

It is shown (SANCHEZ, 2013) that $\alpha$ converges to $\alpha_{\infty}$ and $\beta$ to $\beta_{\infty}$ when the independent variables of the problem $\left(U_{c}, \bar{V}_{x}, W\right.$ and $\left.d\right)$ remain constant on time, provided that parameter $p$ is also constant. In this case, border conditions linked to the solid exchanges at the bottom are exactly satisfied if:

$\beta_{\infty}=0.50 p \alpha$

Complementary, in case of erosion or without exchanges between the bed and the water column $(p \leq 0)$ :

$c_{\beta} \approx 0.667$

Finally, in case of deposition $(p>0)$ :

$c_{\beta} \approx 0.667+0.3 \times \beta_{\infty}$

\section{Methods}

A version $1 \mathrm{DH}$ of the $\alpha-\beta$ model is applied to study the suspended sediment transport in a channel by a unidirectional 2DV flow. The imposed configuration for the channel is shown at the top of Figure 2. This channel comprises an erosion region between $\mathrm{A}$ and $\mathrm{B}$, a deposition region downstream $\mathrm{C}$, and between these two regions (between $\mathrm{B}$ and C) non erosion or deposition is considered. In the simulations, depth $d=2 \mathrm{~m}$ and settling velocity $W=0.001 \mathrm{~m} \mathrm{~s}^{-1}$, are kept constant. In addition, the hydrodynamic transitional phenomena near the discontinuities, are neglected. Table 1 summarizes the main parameters of the studied problem.

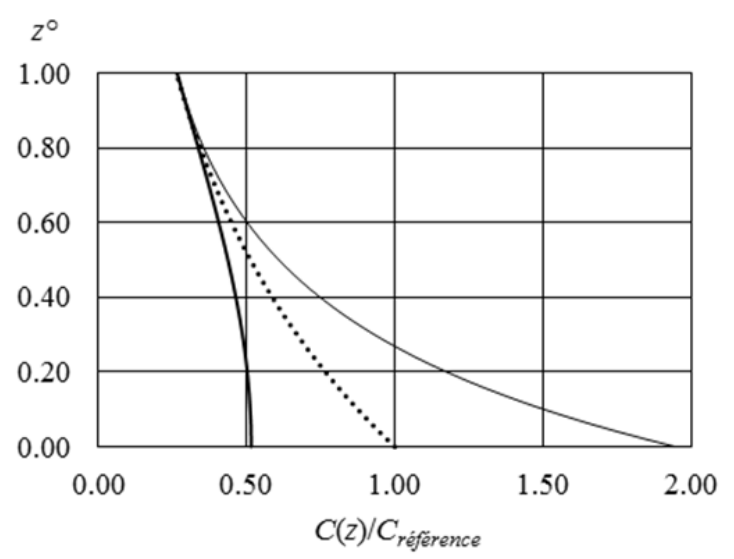

Figure 1. Illustration of the effects of solid exchanges at the bottom on the vertical profile of the suspended sediment concentration. Dotted line: steady state profile. Thick line: profile observed during a deposition period. Thin line: profile observed during an erosion period $\left(\mathrm{z}^{\circ}=0=\right.$ bottom; $\mathrm{z}^{\circ}=1=$ surface $)$. 
Table 1. Summary of hydrosedimentary parameters specific to the studied problem.

\begin{tabular}{llllll}
\hline & Upstream A & Between A \& B & Between B \& $C$ & Between C \& D & Downstream D \\
\hline Flow velocity $\bar{V}_{X}\left(\mathrm{~m} \mathrm{~s}^{-1}\right)$ & 1.28 & 1.28 & 0.64 & 0.32 & 0.32 \\
Shear velocity $U_{c}\left(\mathrm{~m} \mathrm{~s}^{-1}\right)$ & 0.08 & 0.08 & 0.04 & 0.02 & 0.02 \\
Length $(\mathrm{m})$ & undefined & 760 & 760 & 200 & undefined \\
Solid exchange rate, $p$ & 0 & -1 & 0 & +1 & +1 \\
\hline
\end{tabular}
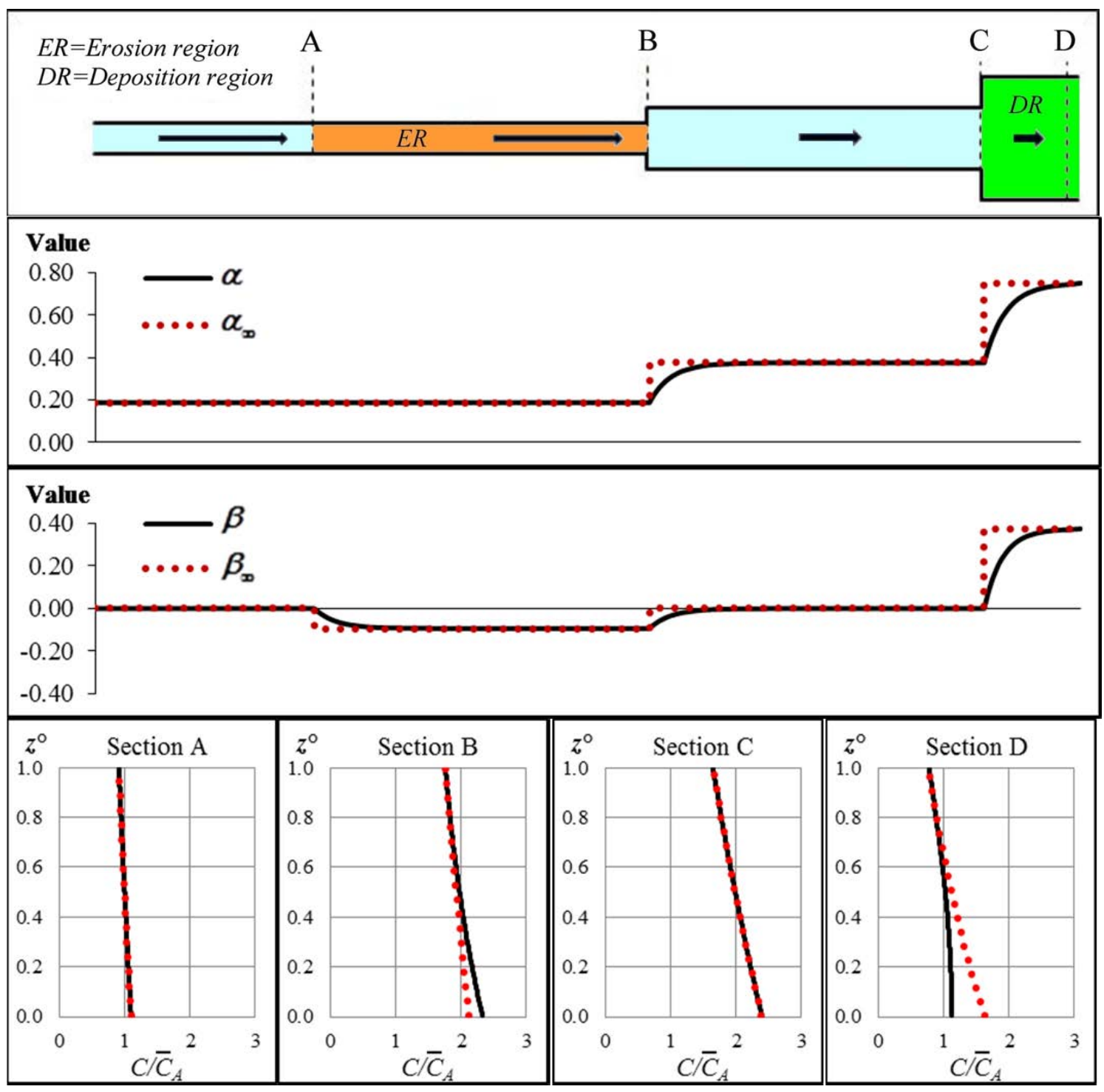

Figure 2. Presentation of results obtained from $\alpha-\beta$ model.

Top: Sketch of the flow studied along a channel.

$2^{\text {nd }}$ row: Evolution of $\alpha$ and $\alpha_{\infty}$, parameters linked to the convective-diffusive mixing.

$3^{\text {rd }}$ row: Evolution of $\beta$ and $\beta_{\infty}$, parameters related to exchanges with the bed.

Bottom: Concentrations reduced by the mean vertical concentration in A as a function of $\mathrm{Z}^{\circ}$, which is shown in the Z-axis; results of $\alpha$ - $\beta$ model are drawn in black line and the exponential distribution with alpha as the only parameter is plotted as a red dotted line. 


\section{Discussion of the obtained results}

Results obtained for the vertical distribution of the concentration are shown for the cross-sections A, B, C and D (Figure 2, bottom).

The profile for the section A represents the border condition of the problem with an average value of $C / \bar{C}_{A}$ equal to 1.00 (where $\bar{C}_{A}$ is the reference concentration upstream the section A). Results from $\alpha$ - $\beta$ model (black line) are in agreement with the law defined by equation 2 for an equilibrium state (red dotted line).

Due to the simulated erosion between $\mathrm{A}$ and $\mathrm{B}$, the average value in $\mathrm{B}$ of $C / \bar{C}_{A}$ reaches about 2.00. It is observed that the concentration at the bottom according to the $\alpha-\beta$ model is greater than that predicted by an equilibrium state equation and this is explained by a supply of sediment from the bed. The value of $\partial C / \partial z$ in $z=0$ is in accordance with the border condition for an erosion parameterized with $p=-1$.

Between sections B and $\mathrm{C}$ a transport in suspension without erosion or deposition is imposed, so that the mean vertical value of $C / \bar{C}_{A}$ remains constant. It gradually moves from a transitory profile downstream $B$ to an equilibrium profile in $C$. In the point $B$ shear velocity changes from $0.08 \mathrm{~m} \mathrm{~s}^{-1}$ to $0.04 \mathrm{~m} \mathrm{~s}^{-1}$, and this causes a redistribution of suspended sediments between $\mathrm{B}$ and $\mathrm{C}$ by increasing sediment accumulation near the bottom. Downstream C, an unhindered free settling is simulated to produce a progressive reduction of the suspended sediments in the flow direction. The vertical mean value of $C / \bar{C}_{A}$ again becomes equal to 1.00 in section $\mathrm{D}$, where it is verified that the vertical profile of the concentration according to the $\alpha-\beta$ model, with $\partial C / \partial z=0$ in $z=0$, is compatible with the border condition for an unhindered deposition, which corresponds to $p=+1$.

On row 2, Figure 2 shows the evolution of the parameters $\alpha$ and $\alpha_{\infty}$, which characterize the convective-diffusive vertical transfers. On the one hand, changes in $\alpha_{\infty}$ close to the flow discontinuities are associated with a locally non-uniform hydrodynamic state. On the other hand, it is noted that following the flow, the model parameter $\alpha$ always converges to its terminal value $\alpha_{\infty}$.

According to the phenomenological law for the variation of $\alpha$ (Eq. 6), if the independent variables of the problem $\left(U_{c}, W\right.$ and $d$ ) remain constant over time and along the flow, the time required to reach a steady state for the vertical distribution of suspended sediments from an arbitrary initial condition can be characterized by a time constant $\tau_{\alpha}=d /\left(c_{\alpha} \times U_{c}\right)$, so that after a time $t=4.6 \times \tau_{\alpha}$ it is observed that: $\left(\alpha_{\infty}-\alpha\right)=\left(\alpha_{\infty}-\alpha_{\text {init }}\right) / 100$, where $\alpha_{\text {init }}$ is the initial value of the parameter $\alpha$ (at $\left.t=0\right)$.

In the case of a non-uniform steady flow as the one studied in this article, the path length $\Lambda_{\alpha}$ associated with a time $t=4.6 \times \tau_{\alpha}$ is:

$$
\Lambda_{\alpha}=\frac{4.6 \times d \times \bar{V}_{X}}{c_{\alpha} \times U_{c}}
$$


Finally, on row 3, Figure 2 shows the evolution of $\beta$ and $\beta_{\infty}$, parameters related to sediment exchanges with the bed. It is observed that the model parameter $\beta$ always converges to its terminal value $\beta_{\infty}$. Variations on $\beta_{\infty}$ are directly linked to variations in the parameter $p$ characterizing these solid exchanges. With erosion or deposition from an arbitrary initial condition characterized by $\beta=\beta_{\text {init }}$ at $t=0$, the path length $\Lambda_{\beta}$ required to observe a $\beta$ value as $\left(\beta_{\infty}-\beta\right)=\left(\beta_{\infty}-\beta_{\text {init }}\right) / 100$, is:

$$
\Lambda_{\beta}=\frac{4.6 \times d \times \bar{V}_{x}}{c_{\beta} \times U_{c}}
$$

For instance, we can cite a specific case with $c_{\alpha}=c_{\beta}=0,667$ and $\bar{V}_{x} / U_{c}=16$, for which computations give $\Lambda_{\alpha}=\Lambda_{\beta}=110 \times d$.

\section{Conclusion}

The numerical simulation carried out with the $\alpha$ - $\beta$ model corresponding to a steady nonuniform flow, shows that the bottom boundary condition related to solid exchanges (erosion and deposition) can adequately be described using Equation 7.

If the parameter $p$ characterizing the solid exchanges with the bed and the independent variables of the problem ( $U_{c}, W$ and $d$ ), all vary gradually along the flow, the vertical distribution of suspended sediment is correctly described using the following simplifications: $\alpha \approx \alpha_{\infty}$ and $\beta \approx \beta_{\infty}$.

More precisely, if variations $\Delta \alpha_{\infty}$ of the parameter $\alpha_{\infty}$ along a length $\Lambda_{\alpha}$ following the flow are everywhere such as $\operatorname{Abs}\left(\Delta \alpha_{\infty} / \alpha_{\infty}\right)<<1$, then everywhere $\alpha \approx \alpha_{\infty}$.

In the same way, if variations $\Delta \beta_{\infty}$ of the parameter $\beta_{\infty}$ along a length $\Lambda_{\beta}$ following the flow are everywhere such as $\operatorname{Abs}\left(\Delta \beta_{\infty} / \beta_{\infty}\right)<<1$, then everywhere $\beta \approx \beta_{\infty}$.

It should be noted that the expressions giving $\Lambda_{\alpha}$ and $\Lambda_{\beta}$ (equations 13 and 14, respectively) are derived from this study.

\section{References}

BERKHOFF J.C.W. (1972). Computation of combined refraction-diffraction. $13^{\text {th }}$ Coastal Engineering Proceedings, ASCE, Vancouver, Canada, pp 471-490.

KRONE R.B. (1986). The significance of aggregate properties to transport processes. In A.J. Mehta (Ed.), Estuarine cohesive sediment dynamics, Coastal and estuarine studies n 14, Springer, Berlin, pp 66-84. http://dx.doi.org/10.1007/978-1-4612-4936-8_4

SAINT-VENANT A. (1871). Théorie du mouvement non permanent des eaux, avec application aux crues des rivières et à l'introduction de marées dans leurs lits. Comptes Rendus de l'Académie des Sciences, Tome 73, Paris, pp 147-154 \& 237-240.

SANCHEZ M. (2013). Nonequilibrium description of the vertical distribution of the suspended sediment transported by open surface flows, considering erosion and deposition phenomena (translated version). Revue Paralia, Vol. 6, pp 9.61-9.90. http://dx.doi.org/10.5150/revue-paralia.2013.009 
s02.8 : Revue Paralia - Vol. 8 (2015)

SANCHEZ M. (2014). Distribution non stationnaire des matières en suspension dans une couche limite oscillant à haute fréquence. XIII ${ }^{\text {ème }}$ Journées Nationales Génie Côtier - Génie Civil, Dunkerque, pp 495-504. http://dx.doi.org/10.5150/jngcgc.2014.054 